\title{
Genetic association between antipsychotic induced weight gain and FTO gene in a Sri Lankan population
}

\author{
V A de Silva ${ }^{1}, K_{\text {K Mneeswaran }}{ }^{1}$, S S Ratnatunga ${ }^{1}$, I Ranwala ${ }^{1}$, S Gamage ${ }^{1}$, R Hanwella ${ }^{1}$, \\ C N Wijeyaratne ${ }^{2}$, N V Chandrasekharan ${ }^{3}$
}

(Index words: FTO, antipsychotic induced weight gain, Sri Lanka, genetic association study)

\begin{abstract}
Background About $30 \%$ of patients treated with second generation antipsychotics (SGA) experience weight gain. Although there is evidence that the FTO gene is associated with obesity its role in antipsychotic induced weight gain is not so clear.

Methods A genetic association study was carried out to identify the association between FTO rs9939609 and antipsychotic induced weight gain. Sample consisted of 180 cases and 120 controls. Cases were patients diagnosed with schizophrenia or schizoaffective disorder, treated with second-generation antipsychotics for a minimum of 3 months, and had gained at least $10 \%$ of body weight. Controls were patients with schizophrenia treated with second-generation antipsychotics for a minimum of 3 months but had not gained $\geq 10 \%$ of body weight. Genomic DNA was extracted from whole blood. Polymerase chain reaction of the samples was done. Real-time quantitative PCR (qPCR) was carried out using BIO-RAD CFX96 Touch $^{\text {TM }}$ PCR detection system.
\end{abstract}

Results Females were significantly more among cases (58.3\%) than controls (35\%). Cases (52.4\%) were significantly more likely to be overweight or obese than controls (13.8\%). Genotype distribution was in Hardy-Weinberg equilibrium $(p=0.43)$. Cochran-Armitage trend test was not significant. Risk of antipsychotic induced weight gain in the AA genotype [OR $1.69(95 \% \mathrm{Cl} 0.74-3.86)]$ and AT genotype [OR 1.1 (95\% Cl 0.67-1.79)] were not significantly higher than the TT genotype. Recessive model showed that AA/AT genotypes were at significantly higher risk of being obese/overweight [OR 1.84 (95\% Cl 1.05-3.2)].

Conclusions There was no significant association between FTO rs9939609 and antipsychotic induced weight gain. AA/AT genotypes had significantly higher risk of overweight/obesity.

Ceylon Medical Journal 2019; 64: 40-45

DOI: http://doi.org/10.4038/cmj.v64i2.8889

\section{Introduction}

Patients with schizophrenia have a higher mortality than the general population $[1,2]$. Cardiovascular disease, cancers and suicide contribute to the higher mortality in this population [3]. Antipsychotic induced weight gain, unhealthy lifestyle, smoking and poor health care utilization and adherence to medication contribute to the increased mortality [3].

Most antipsychotics cause weight gain [4, 5]. In antipsychotic naive patients weight gain starts almost immediately after commencing treatment and continues with time with an increase of 4 BMI points after 24-48 weeks [6]. A recent meta-analysis shows that almost all antipsychotics except amisulpride, aripiprazole and ziprasidone cause weight gain [4]. Increased duration of exposure causes increased weight gain.

Environmental as well as genetic factors are associated with risk of obesity. The importance of lifestyle in obesity is demonstrated by the increasing rates of obesity around the world. Several genetic variants have been associated with obesity and diabetes. Similarly, antipsychotic induced weight gain too is influenced by environmental as well as genetic factors. Study of monozygotic twins and same sex sib pairs suggest a genetic contribution of $60-80 \%$ [7]. A recent meta-analysis found that 13 single nuclear polymorphism (SNPs) from 9 genes were significantly associated with antipsychotic induced weight gain [8]. The largest effect sizes were for SNPs in HTR2C, ADRA2A MC4R and DRD2.

$5 \mathrm{HT} 2 \mathrm{C}$ is a $\mathrm{X}$ linked gene that regulates appetite [9]. A meta-analysis of 10 case control studies found that - $759 \mathrm{~T}$ allele was associated with lower risk of antipsychotic induced weight gain [10]. It is also associated with higher serum fasting glucose and triglycerides [11]. This may be particularly important for antipsychotics which have a high affinity for 5HT2C. The T allele of -759T may

${ }^{1}$ Department of Psychiatry, Faculty of Medicine, University of Colombo, Sri Lanka, ${ }^{2}$ Department of Obstetrics and Gynaecology, Faculty of Medicine, University of Colombo, Sri Lanka, ${ }^{3}$ Department of Chemistry, Faculty of Science, University of Colombo, Sri Lanka.

Correspondence: VADS, e-mail: <vades@psych.cmb.ac.lk>. Received 30 March 2018, revised version received 10 June 2019 and accepted 16 June 2019.

This is an open-access article distributed under the terms of the Creative Commons Attribution License, which permits unrestricted use, distribution, and reproduction in any medium, provided the original author and source are credited. 
be less protective of weight gain in patients treated with clozapine [9].

Leptin is associated with appetite regulation and weight gain. LEP rs7799039 is associated with antipsychotic induced weight gain [12]. However some studies have reported an association with the rs 7799039 G-allele while others have reported an association with the A allele [9].

Three SNPs in the dopamine receptor D2 gene (DRD2) are significantly associated with antipsychotic induced weight gain $[8,13]$. Dopamine D2 receptors may be involved in reward associated with food intake [14].

The human FTO gene is located on chromosome 16q12.2. It spans $410,507 \mathrm{bp}$. The rs9939609 single nucleotide polymorphism (SNP) with nucleotide position " 53786615 " is known to be associated with body mass index (BMI) and type 2 diabetes mellitus [15].

Despite strong evidence that the FTO gene is associated with obesity, its role in antipsychotic induced weight gain is not so clear. Drug metabolism, response and side effects can vary according to ethnicity. There are no studies examining the association between antipsychotic induced weight gain and FTO rs9939609 in South Asians.

\section{Methods}

This genetic association study was carried out with the objective identifying association of FTO rs9939609 polymorphism and antipsychotic induced weight gain in a population of patients of Sri Lankan origin.

\section{Sample selection}

The sample included 180 cases and 120 controls. Cases consisted of patients diagnosed with schizophrenia or schizoaffective disorder, treated with second generation antipsychotics for a minimum of 3 months, and had gained at least $10 \%$ of their body weight. Schizophrenia or schizoaffective disorder were diagnosed according to ICD-10 clinical criteria after a clinical evaluation by a consultant psychiatrist. Gain in body weight was established by comparing the current weight with baseline weight recorded in the clinical records.

Control group consisted of patients with schizophrenia or schizoaffective disorder, treated with second generation antipsychotics for a minimum of three months and had not gained $\geq 10 \%$ of body weight after commencing antipsychotics.

In both cases and controls those concurrently treated with other psychotropic medication known to cause weight gain, (lithium carbonate, carbamazepine, sodium valproate and antidepressants) were excluded.

\section{Study setting}

Patients were recruited from the in-patient and out- patient units of the University Psychiatry Unit, National Hospital of Sri Lanka, Colombo, Sri Lanka.

\section{Sample size calculation}

Quanto genetics sample size calculator developed by the Cornell University USA was used for the sample size estimation and case-control genetic power calculation (http://biostats.usc.edu/Quanto.html). The sample size was calculated to detect an effect size of 1.9 at $80 \%$ power allowing a 5\% type I error rate. 1:1 case-to-control ratio was used. The required sample size was 157 in each group.

\section{Clinical measures}

Height and weight were measured with standard scales. BMI $\left(\mathrm{kg} / \mathrm{m}^{2}\right)$ was calculated. Obesity was defined as $\mathrm{BMI} \geq 25 \mathrm{~kg} / \mathrm{m}^{2}$.

\section{DNA extraction}

Venous blood $(3 \mathrm{ml})$ was collected in an EDTA tube and frozen at $-20^{\circ} \mathrm{C}$ soon after collection. DNA extraction was carried out within a week after collection. Genomic DNA from the whole blood $(300 \mu \mathrm{L})$ was extracted using the Wizard ${ }^{\circledR}$ Genomic DNA Purification Kit (Promega) as per manufacturers instruction. An aliquot of extracted DNA was loaded into $0.8 \%$ EtBr stained agarose gel and electrophoresis was carried out to determine the quality of the DNA. Extracted DNA was stored at $-20^{\circ} \mathrm{C}$ until further use.

\section{Quantitative PCR}

The real-time quantitative PCR (qPCR) was carried out using BIO-RAD CFX96 Touch $^{\text {TM }}$ PCR detection system. Polymerase chain reaction targeted the SNP ID: rs9939609 on chromosome 16.

SNP genotyping analysis was carried out using the Taqman genotyping assays from Thermofisher (http:// www.thermofisher.com/lk/en/home/life-science/pcr/realtime-pcr/real-time-pcr-assays/snp-genotyping-taqmanassays.html). Briefly, dbSNP id (rs9939609) was used as the input to find the appropriate product for genotyping the SNP in FTO gene using theTaqMan ${ }^{\circledR}$ assay search tool. The context sequence for this assay is: [VIC/FAM] GGTTCCTTGCGACTGCTGTGAATTT[A/T] GTGATGCACTTGGATAGTCTCTGTT

The TaqMan ${ }^{\circledR}$ Predesigned SNP Genotyping Assay included two allele-specific TaqMan ${ }^{\circledR}$ MGB probes (minor groove binding) containing one $\mathrm{VIC}^{\circledR}$-labeled probe to detect Allele $\mathrm{A}$ and one $\mathrm{FAM}^{\mathrm{TM}}$-labeled probe to detect Allele T, two target-specific forward and reverse PCR primers. MGB probes also included a non-fluorescent quencher (NFQ).

The qPCR was carried out in a volume of $20 \mu \mathrm{L}$ and contained $10 \mu \mathrm{L}$ of $2 \mathrm{X}$ TaqMan ${ }^{\circledR}$ Genotyping Master Mix, $1 \mu \mathrm{L}$ of $20 \mathrm{X}$ TaqMan ${ }^{\circledR}$ Genotyping Assay working stock, 1 
$\mu \mathrm{L}$ of $(20 \mathrm{ng} / \mu \mathrm{L})$ purified genomic DNA per well, and $8 \mu \mathrm{L}$ PCR water. In each assay a no template control (NTC) containing $1 \mu \mathrm{L}$ of PCR water instead of template DNA and a Negative Control (NC) containing all components except the DNA polymerase were included.

The cycling parameters were as follows: initial denaturation at $95^{\circ} \mathrm{C}$ for $10 \mathrm{~min}$, followed by 25 cycles of denaturation at $95^{\circ} \mathrm{C}$ for 15 seconds and annealing/ extension at $60^{\circ} \mathrm{C}$ for 45 seconds.

The allelic discrimination analysis was carried out using CFX manager software. It generates an allelic discrimination plot from the plate-read data with Allele A $\left(\mathrm{VIC}^{\circledR}\right.$ dye $)$ on the $\mathrm{X}$ axis and Allele $\mathrm{T}\left(\mathrm{FAM}^{\mathrm{TM}}\right.$ dye $)$ on the $\mathrm{Y}$ axis. Each well of the 96-well reaction plate is represented as an individual point on the plot as shown in Figure 1.

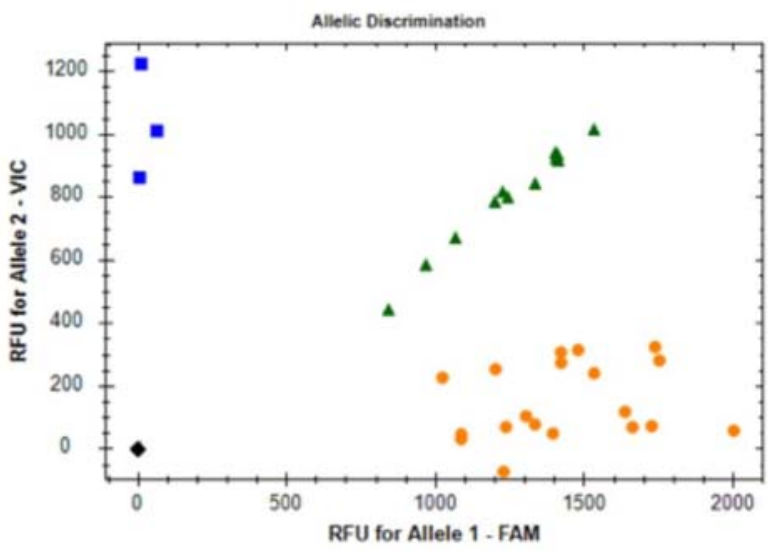

Figure 1. Allelic discrimination.

\section{Ethics approval}

Ethical clearance was obtained from the Ethics Review Committee, Faculty of Medicine, University of Colombo (EC/16/004). Written informed consent was obtained from all participants.

\section{Statistical analysis}

Differences in means were determined using the Student's t-test. Associations between categorical variables were determined using Chi square tests. Logistic regression and Cochran-Armitage trend testwere used to assess the risk of weight gain in the different genotypes.

We tabulated the number of cases and controls with each genotype AA, AT, and TT. The dominant, recessive models were developed with the assumption that the risk of antipsychotic induce weight gain decreases when the number of $\mathrm{T}$ alleles increase. The dominant model compared AA genotype to the AT+TT genotype. The Recessive model compared the AA+ AT genotypes to the TT genotype. The Pearson's chi-square test was used to assess the associations with the dominant and recessive models. The Cochran-Armitage trend test were used to identify any trends in the association between genotypes and the risk of weight gain.

Statistical analysis was carried out using SPSS version 10.

\section{Results}

The study group consisted of 180 cases and 120 controls (Table 1). There were significantly more females in the case group ( $\mathrm{n}=105,58.3 \%)$ than in the control group $(\mathrm{n}=42,35 \%)\left(\chi^{2} 15.69 \mathrm{df}=1, \mathrm{p}<0.001\right)$. The case group had a significantly higher proportion of patients who were overweight or obese $(\mathrm{BMI}>25)\left(\chi^{2}=36.42, \mathrm{df}=1, \mathrm{p}<0.001\right)$. There was no significant difference in age between the case and control groups $(\mathrm{t}=0.897, \mathrm{p}=0.37)$.

The genotype distribution was in Hardy-Weinberg equilibrium ( $\mathrm{p}=0.43$ ). Minor allele frequency (A) was 0.35 . In the case group the variant allele frequency was $\mathrm{A}=0.36$, $\mathrm{T}=0.64$ and in controls $\mathrm{A}=0.32, \mathrm{~T}=0.68$ (Table 2$)$.

Table 1. Characteristics of the study sample

\begin{tabular}{lll}
\hline & Cases $N(\%)$ & Controls $N(\%)$ \\
\hline Age (mean) & $\begin{array}{l}41.34 \text { years } \\
(\mathrm{SD}=13.49)\end{array}$ & $\begin{array}{l}42.76 \text { years } \\
(\mathrm{SD}=13.07)\end{array}$ \\
Sex & & \\
Male & $75(41.7)$ & $78(65 \%)$ \\
Female & $105(58.3)$ & $42(35 \%)$ \\
Treatment & & \\
Clozapine & $39(23.4)$ & $38(32.8)$ \\
Olanzapine & $58(34.7)$ & $28(24.1)$ \\
Risperidone & $70(41.9)$ & $50(43.1)$ \\
BMI (mean) & $25.24 \mathrm{~kg} / \mathrm{m}^{2}$ & $21.07 \mathrm{~kg} / \mathrm{m}^{2}$ \\
& $(\mathrm{SD} 4.20)$ & $(\mathrm{SD} 3.30)$ \\
Overweight/obese & $77(52.4)$ & $13(13.8)$ \\
Diabetes & $28(15.6)$ & $18(15.0)$ \\
\hline
\end{tabular}

Table 2. Genotype distribution in case and control groups

\begin{tabular}{lrrr}
\hline & $A A$ & $A T$ & $T T$ \\
\hline Cases & 23 & 85 & 72 \\
Controls & 10 & 57 & 53 \\
Total & 33 & 142 & 125 \\
\hline
\end{tabular}

\section{Risk of antipsychotic induced weight gain in different} genotypes

There was no significant difference in mean BMI between the AA (24.22), AT (24.15) and TT (22.77) genotypes (Table 3). Risk of antipsychotic induced weight 
gain in the AA genotype [OR 1.69 (95\% CI 0.74-3.86)] and AT genotype [OR 1.1 (95\% CI 0.67-1.79)] were not significantly higher than the TT genotype. CochranArmitage trend test was not significant $\left(\chi^{2}=1.23 \mathrm{DF}=1\right.$, $\mathrm{P}=0.27)$. There was no difference in gender distribution between the 3 genotypes $\left(\chi^{2}=3.23 \mathrm{DF}=2, \mathrm{p}=0.20\right)$.

Table 3. Characteristics according to genotype distribution

\begin{tabular}{lccc}
\hline & $A A$ & $A T$ & $T T$ \\
\hline BMI & 24.10 & $\begin{array}{c}24.14 \\
(\text { SD } 4.0)\end{array}$ & $\begin{array}{c}22.77 \\
(S D ~ 4.68)\end{array}$ \\
Gender & & & \\
Male & $12(7.8)$ & $74(48.4)$ & $67(43.8)$ \\
Female & $21(14.3)$ & $68(46.3)$ & $58(39.5)$ \\
\hline
\end{tabular}

Dominant model comparing genotypes AA with AT/TT showed that AA does not carry significantly high risk of antipsychotic induced weight gain [OR 1.61 (95\% CI 0.73-3.5)] (Table 4).

Recessive model comparing genotypes AA/AT with TT showed that AA/AT does not carry significantly high risk of weight gain OR 1.187 (95\% CI 0.74-1.89) (Table 5). The dominant [OR 1.54 (95\% CI 0.64-3.7)] and recessive models [OR 1.03 (95\% CI 0.61-31.72)] did not show any significance when they were adjusted for obesity.

Table 4. Dominant model for antipsychotic induced weight gain

\begin{tabular}{|c|c|c|c|}
\hline & Case & $N=180$ & Control $N=120$ \\
\hline $\mathrm{AA} / \mathrm{AT}$ & & 23 & 10 \\
\hline $\mathrm{TT}$ & & 157 & 110 \\
\hline
\end{tabular}

Table 5. Dominant model for antipsychotic induced weight gain

\begin{tabular}{|c|c|c|}
\hline & Case $N=180$ & Control $N=120$ \\
\hline $\mathrm{AA} / \mathrm{AT}$ & 108 & 67 \\
\hline TT & 72 & 53 \\
\hline
\end{tabular}

\section{Risk of obesity according to genotype}

We analysed the risk of being obese according to the genotype. The recessive model showed that those with AA/AT genotypes were at significantly higher risk of being obese/overweight (BMI>25) OR 1.84 (95\% CI 1.05-3.2) (Table 6). The dominant model was not significantly associated with obesity [OR 0.72 (95\% CI 0.33-1.6).
Table 6. Association between genotype and obesity using the recessive model

\begin{tabular}{lcc}
\hline & Obese $N(\%)$ & Normal $N(\%)$ \\
\hline AA /AT & $62(38.0)$ & $101(62.0)$ \\
TT & $32(26.9)$ & $87(73.1)$ \\
Total & 94 & 188 \\
\hline
\end{tabular}

\section{Discussion}

This study did not find a significant association between FTO rs9939609 and antipsychotic induced weight gain using the dominant, recessive or multiplicative models. However, we found that AA/AT genotypes (recessive model) had significantly higher risk of overweight/obesity. The minor allele frequency was 0.35 .

The FTO gene was the first gene associated with obesity [16]. Studies since have confirmed this association. Because of its strong association with obesity it was also investigated for antipsychotic induced weight gain. Most studies have not found an association between FTO rs9939609 and antipsychotic induced weight gain. PerezIglesias et al reported in a study of 239 first episode patients that baseline BMI was higher among the AA homozygotes but there was no significant difference in weight gain between the 3 genotypes after one year of treatment [17]. Shing et al reported that in patients with chronic schizophrenia or schizoaffective disorder there was no significant association between FTO gene and antipsychotic induced weight gain [13]. Reynolds et al. also did not find an association between the SNP and antipsychotic induced weight gain in first episode patients [18]. A meta-analysis of longitudinal studies did not find a significant association between of FTO rs9939609 and antipsychotic induced weight gain [8].

However, Song et al. reported that in first episode Han Chinese patients treated with risperidone for 6 months, antipsychotic induced weight gain was significantly lower in TT homozygotes than A allele carriers of rs9939609 [19]. Reynolds et al. reported that in chronic patients BMI was associated with the FTO genotype. Genome-wide association studies of the Clinical Antipsychotic Trials of Intervention Effectiveness (CATIE) study sample which investigated 1084 SNPs across 31 obesity related genes found two SNPs FTO rs9922047, and rs11643744 were associated with antipsychotic induced weight gain [20]. These two SNPs were in linkage disequilibrium with rs9939609. The authors suggest that the larger sample size and ethnic differences could account for difference in findings in the Clinical Antipsychotic Trials of Intervention Effectiveness(CATIE) study.

We too did not find an association with antipsychotic induced weight gain but found that the AA/AT genotypes had a significantly higher BMI. This may be because the 
mechanism of antipsychotic induced weight gain is different to that of weight gain in obesity. Second generation antipsychotics probably cause weight gain by acting on receptors which are involved in food intake and fat metabolism such as $5 \mathrm{HT} 2 \mathrm{C}$ and DRD2 genes. It is speculated that the FTO gene is involved in fat accumulation and insulin resistance [21]. However, it does not code for receptors which the antipsychotics act on. This may explain why it is not associated with anti-psychotic induced weight gain.

Genome-wide association studies (GWAS) have identified several genes associated with antipsychotic induced weight gain. In most cases the associations have not been replicated in subsequent studies and the function of most genes so identified are unknown. For example, genome-wide association studies in a subset of the CATIE sample found significant association with SNP rs9346455 located on opioid growth factor receptor-like 1 gene (OGFRL1) on chromosome 6 [12]. This association has not been previously described.

Ethnic variation between study samples also influence the outcome. There is strong evidence of association between BMI and FTO in white Caucasians as well as Asian Indians [16, 22]. The evidence is not so strong for ethnic Chinese. A study of ethnic Chinese found no significant association between the FTO rs9939609 and obesity, overweight or diabetes mellitus [23]. The minor allele frequency in this Chinese population was 0.12 . Among Indians the minor allele frequency was 30-33\% which is similar to that in our study [22].

Inconsistent results of association of antipsychotic induced weight gain with genes may be due to several factors. The risk of weight gain and the receptor binding profile of different antipsychotics vary substantially between second generation antipsychotics. Thus it is possible that antipsychotics may induce weight gain through different mechanisms. Therefore, the genes involved in antipsychotic induced weight gain may differ according to the antipsychotic. This aspect has not been investigated in detail. Mechanisms of weight gain in first episode patients and those on long term treatment may also differ [24]. Although there are some studies of first episode patients most genetic association studies have used mixed populations. It is also possible that the mechanism of antipsychotic induced weight gain may vary between males and females.

The genetic contribution to obesity and antipsychotic induced weight gain is polygenic. A meta-analysis reported that 32 confirmed loci explained $1.45 \%$ of variance in BMI. FTO gene accounted for the largest proportion of $0.34 \%$ [25]. However, such risk calculations cannot be made for antipsychotic induced weight gain because the contribution of the individual SNPs have not been clearly identified. Therefore, it is not yet possible to work out the genetic risk of antipsychotic induced weight gain to an individual.

\section{Conclusions}

This study did not find a significant association between FTO rs9939609 and antipsychotic induced weight gain in a Sri Lankan population using the dominant, recessive or multiplicative models. However, AA/AT genotypes had significantly higher risk of overweight/ obesity.

\section{Conflict of interests}

The authors declare that they have no conflict of interests.

\section{Funding}

This research was funded by the National Research Council of Sri Lanka grant 13-042. The funding body did not have any role in the design of the study and collection, analysis, and interpretation of data and in writing the manuscript.

\section{References}

1. Hennekens CH, Hennekens AR, Hollar D, Casey DE. Schizophrenia and increased risks of cardiovascular disease. Am Heart J 2005; 150(6): 1115-21.

2. Saha S, Chant D, McGrath J. A systematic review of mortality in schizophrenia: is the differential mortality gap worsening over time? Arch Gen Psychiatry 2007; 64(10): 1123-31.

3. Correll CU, Detraux J, De Lepeleire J, De Hert M. Effects of antipsychotics, antidepressants and mood stabilizers on risk for physical diseases in people with schizophrenia, depression and bipolar disorder. World Psychiatry 2015; 14(2): 119-36.

4. Allison DB, Mentore JL, Heo M, et al. Antipsychoticinduced weight gain: a comprehensive research synthesis. Am J Psychiatry 1999; 156(11): 1686-96.

5. Bak M, Fransen A, Janssen J, van Os J, Drukker M. Almost all antipsychotics result in weight gain: a metaanalysis. PLoS One 2014; 9(4): e94112.

6. Tarricone I, Ferrari Gozzi B, Serretti A, Grieco D, Berardi D. Weight gain in antipsychotic-naive patients: a review and meta-analysis. Psychol Med 2010; 40(2): 187-200.

7. Gebhardt S, Theisen FM, Haberhausen M. Body weight gain induced by atypical antipsychotics: an extension of the monozygotic twin and sib pair study. J Clin Pharm Ther 2010; 35(2): 207-11.

8. Zhang JP, Lencz T, Zhang RX, Nitta M, Maayan L et al. Pharmacogenetic Associations of Antipsychotic DrugRelated Weight Gain: A Systematic Review and Metaanalysis. Schizophr Bull 2016; 42(6): 1418-37.

9. De Luca V, Mueller DJ, de Bartolomeis A, Kennedy JL. Association of the HTR2C gene and antipsychotic induced weight gain: a meta-analysis. Int J Neuropsychopharmacol 2007; 10(5): 697-704. 
10. Reynolds GP. Pharmacogenetic Aspects of Antipsychotic Drug-induced Weight Gain - A Critical Review. Clin Psychopharmacol Neurosci 2012; 10(2): 71-7.

11. Kuzman MR, Medved V, Bozina N, Grubisin J, Jovanovic N, Sertic J. Association study of MDR1 and 5-HT2C genetic polymorphisms and antipsychotic-induced metabolic disturbances in female patients with schizophrenia. Pharmacogenomics $J$ 2011; 11(1): 35-44.

12. Brandl EJ, Frydrychowicz C, Tiwari AK, et al. Association study of polymorphisms in leptin and leptin receptor genes with antipsychotic-induced body weight gain. Prog Neuropsychopharmacol Biol Psychiatry 2012; 38(2): 134-41.

13. Shing EC, Tiwari AK, Brandl EJ, et al. Fat mass- and obesity-associated (FTO) gene and antipsychotic-induced weight gain: an association study. Neuropsychobiology 2014; 69(1): 59-63.

14. Wang GJ, Volkow ND, Fowler JS. The role of dopamine in motivation for food in humans: implications for obesity. Expert Opin Ther Targets 2002; 6(5): 601-9.

15. Baik I, Shin C. Interactions between the FTO rs 9939609 polymorphism, body mass index, and lifestyle-related factors on metabolic syndrome risk. Nutr Res Pract 2012; 6(1): 78-85.

16. Frayling TM, Timpson NJ, Weedon MN, et al. A common variant in the FTO gene is associated with body mass index and predisposes to childhood and adult obesity. Science 2007; 316(5826): 889-94.

17. Perez-Iglesias R, Mata I, Amado JA, et al. Effect of FTO, SH2B1, LEP, and LEPR polymorphisms on weight gain associated with antipsychotic treatment. J Clin Psychopharmacol 2010; 30(6): 661-6.
18. Reynolds GP, Yevtushenko OO, Gordon S, Arranz B, San L, Cooper SJ. The obesity risk gene FTO influences body mass in chronic schizophrenia but not initial antipsychotic drug-induced weight gain in first-episode patients. Int $J$ Neuropsychopharmacol 2013; 16(6): 1421-5.

19. Song X, Pang L, Feng Y, et al. Fat-mass and obesityassociated gene polymorphisms and weight gain after risperidone treatment in first episode schizophrenia. Behav Brain Funct 2014; 10(1): 35.

20. Tiwari HK, Patki A, Lieberman J, et al. Association of Allelic Variation in Genes Mediating Aspects of Energy Homeostasis with Weight Gain during Administration of Antipsychotic Drugs (CATIE Study). Front Genet 2011; 2: 56.

21. Kim YJ, Lee HS, Kim YK, et al. Association of Metabolites with Obesity and Type 2 Diabetes Based on FTO Genotype. PLoS One 2016; 11(6): e0156612.

22. Vasan SK, Karpe F, Gu HF, et al. FTO genetic variants and risk of obesity and type 2 diabetes: a meta-analysis of 28,394 Indians. Obesity (Silver Spring) 2014; 22(3): 964-70.

23. Huaixing Li YW, Loos RJF, Hu FB, Wang YLJ, Yu Z, Lin $\mathrm{X}$. Variants in the Fat Mass- and Obesity-Associated (FTO)Gene Are Not Associated With Obesity in a Chinese Han Population. Diabetes 2008; 57: 264-8.

24. de Silva VA, Suraweera C, Ratnatunga SS, Dayabandara M, Wanniarachchi N, Hanwella R. Metformin in prevention and treatment of antipsychotic induced weight gain: a systematic review and meta-analysis. BMC Psychiatry 2016; 16(1): 341.

25. Speliotes EK, Willer CJ, Berndt SI, et al. Association analyses of 249,796 individuals reveal 18 new loci associated with body mass index. Nat Genet 2010; 42(11): 937-48. 